\title{
The prevalence of homologous recombination deficiency (HRD) in various solid tumors and the role of HRD as a single biomarker to immune checkpoint inhibitors
}

\author{
Hana Kim ${ }^{1}$. Soomin Ahn ${ }^{2}$. Hongsik Kim ${ }^{1}$. Jung Yong Hong ${ }^{1}$. Jeeyun Lee ${ }^{1}$. Se Hoon Park ${ }^{1}$ Joon Oh Park ${ }^{1}$. \\ Young Suk Park ${ }^{1} \cdot$ Ho Yeong Lim ${ }^{1} \cdot$ Won Ki Kang ${ }^{1} \cdot$ Kyoung-Mee Kim² ${ }^{2}$ Seung Tae Kim ${ }^{1}$ (D)
}

Received: 22 April 2021 / Accepted: 21 August 2021 / Published online: 12 September 2021

(c) Crown 2021

\begin{abstract}
Purpose Homologous recombination deficiency (HRD) is related to tumorigenesis. Currently, the possibility of HRD as a prognostic biomarker to immune checkpoint inhibitors is unknown. We aimed to investigate whether HRD has potential as a biomarker for immunotherapy.

Methods The status of homologous recombination deficiency (HRD) was assessed with the next-generation sequencing (NGS) TruSight ${ }^{\mathrm{TM}}$ Oncology 500 assay in 501 patients with advanced solid tumor including gastrointestinal (GI), genitourinary (GU), or rare cancer. Results: among the 501 patients, HRD was observed as follows: 74.7\% (347/501) patients; GU cancer $(92.0 \%, 23$ of 25), colorectal cancer (CRC) $(86.1 \%, 130$ of 151), hepatocellular carcinoma (HCC) $(83.3 \%, 10$ of 12), pancreatic cancer (PC) $(76.2 \%, 32$ of 42), biliary tract cancer (BTC) $(75.0 \%, 36$ of 48$)$, sarcoma $(65.0 \%, 39$ of 60$)$, melanoma $(52.4 \%, 11$ of 21$)$, other GI cancers $(50.0 \%, 11$ of 22$)$, and rare cancer $(50.0 \%, 2$ of 4$)$. Sixty-five of the 501 patients had received immune checkpoint inhibitors (ICIs) during the course of the disease. Tumor types of 65 patients treated with ICIs are as follows: melanoma $(95.2 \%, 20$ of 21$), \operatorname{HCC}(33.3 \%, 4$ of 12$)$, rare cancer $(25.0 \%, 1$ of 4$)$, GC $(12.2 \%, 14$ of 116$)$, BTC $(10.4 \%, 5$ of 48$)$, and sarcoma (5.0\%, 3 of 60$)$. The most frequently reported mutations were BRCA2 $(n=90), A R I D I A$ $(n=77), A T M(n=71), B A R D 1$ ( $n=67)$. Patients without HRD exhibited an objective response rate (ORR) of $33.3 \%$ (4 of 12$)$, and patients with HRD exhibited an ORR of $34.0 \%$ (18 of 53). There was no significant difference in ORR between patients with and without HRD $(P=0.967)$. Progression-free survival (PFS) was 6.5 months (95\% CI 0.000-16.175) in patients without HRD and 4.1 months (95\% CI 2.062-6.138) in patients with HRD, revealing no statistical significance $(P=0.441)$. Conclusion Herein, we reported the status of HRD using a cancer-panel for various solid tumor patients in routine clinical practice and demonstrated that HRD as a single biomarker was not sufficient to predict efficacy of ICIs in solid tumor patients.
\end{abstract}

Keywords HRD · NGS · Cancer immunotherapy · Checkpoint inhibitor

\section{Abbreviations}

BTC Biliary tract cancer

CRC Colorectal cancer

Hana Kim, Soomin Ahn: equally contributed and co-first authors.

Seung Tae Kim

shty1@ skku.edu

1 Division of Hematology-Oncology, Department of Medicine, Samsung Medical Center, Sungkyunkwan University School of Medicine, 81 Irwon-ro, Gangnam-gu, Seoul 06351, Korea

2 Department of Pathology and Translational Genomics, Samsung Medical Center, Sungkyunkwan University School of Medicine, 81 Irwon-ro, Gangnam-gu, Seoul 06351, Korea

$\begin{array}{ll}\text { DDR } & \text { DNA damage repair } \\ \text { FFPE } & \text { Formalin-fixed paraffin-embedded } \\ \text { GU } & \text { Genitourinary } \\ \text { HCC } & \text { Hepatocellular carcinoma } \\ \text { HRD } & \text { Homologous recombination deficiency } \\ \text { ICIs } & \text { Immune checkpoint inhibitors } \\ \text { MSI } & \text { Microsatellite instability } \\ \text { NGS: PC } & \text { Pancreatic cancer next-generation sequencing } \\ \text { ORR } & \text { Objective response rate } \\ \text { PFS } & \text { Progression-free survival } \\ \text { RCC } & \text { Renal cell carcinoma } \\ \text { TMB } & \text { Tumor mutational burden }\end{array}$




\section{Background}

After immune checkpoint inhibitors (ICIs) were introduced for treatment of solid tumors, they exhibited improved survival and treatment outcomes compared to traditional non-immune anti-cancer therapies, especially for patients with advanced melanoma, non-small-cell lung cancer (NSCLC), urothelial cancer (UC), renal cell carcinoma (RCC), or other cancer types (Borghaei et al. 2015; Hodi et al. 2010; Motzer et al. 2015, 2018; Nghiem et al. 2016; Rosenberg et al. 2016; Wolchok et al. 2013). However, only some patients achieved a response to ICIs. This indicates the need for further development of immunerelevant biomarkers to identify patients who might benefit from immunotherapy.

The DNA damage repair (DDR) system is essential to maintain the integrity of the genome in organisms. Genomic alteration due to failure to repair DDR causes tumor initiation. The homologous recombination (HR) pathway has a substantial influence on genomic integrity and germline mutations in this pathway and is related to tumorigenesis (Bartkova et al. 2005; Jeggo et al. 2016; Khanna 2015). Homologous recombination is one of the major repair mechanisms of DNA double-strand breaks. Homologous recombination deficiency (HRD) is a DNA repair deficiency related to tumorigenesis and causes increased sensitivity to platinum-based chemotherapy and PARP inhibitors (Watkins et al. 2014). The concept of therapy-directed HRD is approved in ovarian and breast cancers. The mutation in the HR pathway related to $B R C A 1 / 2$ was used to predict better objective response rates to platinum-based chemotherapy in advanced triplenegative breast cancer (Tutt et al. 2018).

Recently, targeted cancer gene panel assay or NGS for HRD has been performed in clinical settings. These panels assess genomic profiles including Tumor Mutational Burden (TMB), Microsatellite Instability (MSI), and HRD. To date, the clinical significance of gene mutations related to HRD has not been studied well across various solid tumors. Herein, we analyzed the status of HRD using cancer panels for various solid tumor patients in routine clinical practice and determined the value of HRD as a biomarker of response to ICIs.

\section{Methods}

\section{Patients}

Patients with pathologic confirmation of advanced gastrointestinal, GU, or rare cancers at Samsung Medical Center between Oct 2019 and Mar $2020(n=501)$, were prospectively tested for molecular aberrations, including TMB, with the TruSight ${ }^{\mathrm{TM}}$ Oncology 500 assay. All study participants provided written informed consent before study entry. The following clinicopathologic characteristics were collected for all patients: age, sex, primary tumor site, number of metastatic sites, site of metastasis, treatment, and survival. The study protocol was approved (\#2020-11-151) by the Institutional Review Board of Samsung Medical Center (Seoul, Korea) and was conducted in accordance with the ethical principles of the Declaration of Helsinki and the Korea Good Clinical Practice guidelines. All patients provided written informed consent before enrollment. Written informed consent included disclosure of information, competency to make a decision, and voluntary nature of the decision for the purpose, benefit, and potential risk of this study.

\section{Tumor samples}

Samples for analysis were collected from 501 solid tumors and prepared as formalin-fixed paraffin-embedded (FFPE) material. The samples were gathered through biopsy at diagnosis, surgical specimen, or repeat biopsy at the time of disease progression; all were obtained before immunotherapy. The types of samples used in the analysis were as follows: biopsied samples $(n=320,63.9 \%)$ and surgically resected samples $(n=181,36.1 \%)$.

\section{TruSight $^{\mathrm{Tm}}$ oncology 500assay}

Forty (40) ng of DNA was quantified with the Qubit dsDNA HS Assay (Thermo Fisher Scientific) on the Qubit 2.0 Fluorometer (Thermo Fisher Scientific) and then sheared using a Covaris E220 Focused-ultrasonicator (Woburn, MA, USA) and the 8 microTUBE-50 Strip AFA Fiber V2 following the manufacturer's instructions. Treatment time was optimized for FFPE material. The treatment settings were as follows: peak incident power (W): 75 ; duty factor: $15 \%$; cycles per burst: 500 ; treatment time (s): 360 ; temperature $\left({ }^{\circ} \mathrm{C}\right): 7$; and water level: 6. For DNA library preparation and enrichment, the TruSight ${ }^{\mathrm{TM}}$ Oncology 500 Kit (Illumina) was used following the manufacturer's instructions. Post-enriched libraries were quantified, pooled, and sequenced on a NextSeq 500 (Illumina Inc., San Diego, CA, USA). The quality of the NextSeq 500 (Illumina) sequencing runs was assessed with the Illumina Sequencing Analysis Viewer (Illumina). Sequencing data were analyzed with the TruSight ${ }^{\mathrm{TM}}$ Oncology 500 Local App Version 1.3.0.39 (Illumina), a comprehensive tumor profiling assay designed to identify known and emerging tumor biomarkers, including small variants, splice variants, and fusions. The reads were aligned to the reference genome (GRCh37/hg19) using Burrows - Wheeler Aligner-MEM (BWA-MEM) (Li 2013). Poorly mapped reads with a mapping quality (MAPQ) below 20 were removed using Samtools version 1.3.1(Li et al. 2009). Somatic mutations including single-nucleotide variants (SNV) and small 
insertions and deletions (INDELs) were detected by the Pisces and Psara (Dunn et al. 2019). The rest of pipeline are as follows: CRAFT for copy number variation, TmbRaider for TMB, Hubble for MSI, STAR for RNA alignment, and Manta for fusion calling (Pestinger et al. 2020). Outputs of data, exported from The TSO 500 pipeline (Pestinger et al. 2020) were annotated with Ensembl Variant Effect Predictor (VEP) Annotation Engine, with information from the databases, such as dbSNP, gnomAD genome and exome, 1000 genomes, ClinVar, COSMIC, RefSeq, and Ensembl. The processed genomic alterations were categorized with four-tier system by American Society of Clinical Oncology and College of American Pathologists (Li et al. 2017), annotated with proper reference. The following criteria were used to filter our less significant variants and possible germline variants: (i) variants $<5 \%$ allele frequency and $<100 \times$ read depth at the variant were excluded; (ii) variants previously

Table 1 Characteristics of 501 patients with various solid tumors

\begin{tabular}{|c|c|}
\hline & All patients $(N=501)$ \\
\hline \multicolumn{2}{|l|}{ Age (year) } \\
\hline Median (range) & $59.7(21-86)$ \\
\hline \multicolumn{2}{|l|}{ Sex } \\
\hline Male & $302(60.3 \%)$ \\
\hline Female & $199(39.7 \%)$ \\
\hline \multicolumn{2}{|l|}{ Tumor type } \\
\hline Colorectal cancer & 151 \\
\hline Gastric cancer & 116 \\
\hline Sarcoma & 60 \\
\hline Biliary tract cancer & 48 \\
\hline Pancreatic cancer & 42 \\
\hline Genitourinary cancer & 25 \\
\hline Other GI tract cancer & 22 \\
\hline Melanoma & 21 \\
\hline Hepatocellular carcinoma & 12 \\
\hline Rare cancer & 4 \\
\hline \multicolumn{2}{|c|}{ Tumor mutational burden (TMB) } \\
\hline TMB low & $443(88.4 \%)$ \\
\hline TMB-high & $58(11.6 \%)$ \\
\hline \multicolumn{2}{|c|}{ Microsatellite instability (MSI) } \\
\hline Non-MSI & $494(98.6)$ \\
\hline MSI & $7(1.4)$ \\
\hline \multicolumn{2}{|l|}{ PD-L1 $(N=225)$} \\
\hline Positive & $101(20.2)$ \\
\hline Negative & $124(24.8)$ \\
\hline \multicolumn{2}{|c|}{ Homologous recombination (HR) } \\
\hline Deficiency & $375(74.9 \%)$ \\
\hline Non-deficiency & $126(25.1 \%)$ \\
\hline \multicolumn{2}{|l|}{ Receiving ICIs } \\
\hline Yes & $65(13.0 \%)$ \\
\hline No & $436(87.0 \%)$ \\
\hline
\end{tabular}

reported to be benign or likely benign in the ClinVar archive (Landrum et al. 2016) were excluded; (iii) variant with a frequency greater than $1 \%$ in gnomAD (Karczewski et al. 2020) were excluded.

Importantly, the TruSight ${ }^{\mathrm{TM}}$ Oncology 500 measures homologous recombination deficiency (HRD). The HRDrelated genes were as follows: ARIDIA, ATM, ATRX, BAP1, BARD1, BLM, BRCA1, BRCA2, BRIP1, CHEK1, CHEK2, FANCA, FANCC, FANCD2, FANCE, FANCF, FANCG, FANCL, MRE11A, NBN, PALB2, PTEN, RAD50, RAD51, and $R A D 51 B$. Homologous recombination deficiency was diagnosed if there was at least one HR-related gene mutation.

\section{Statistical analyses and disease evaluation}

All statistical analyses were conducted with SPSS statistics 27. Descriptive statistics are reported as proportion and

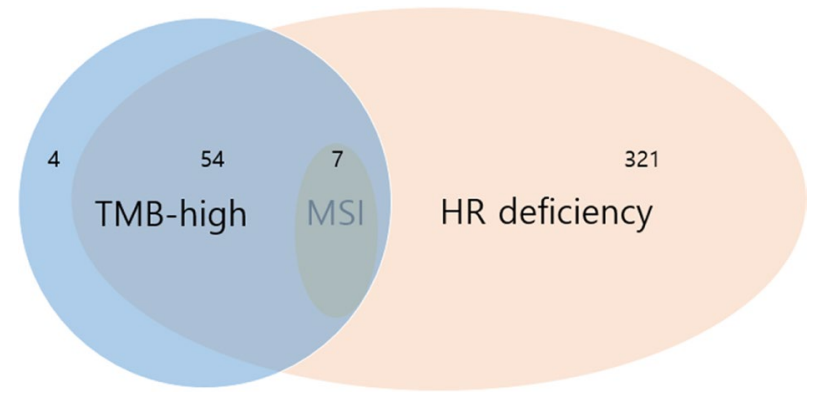

Fig. 1 Distributions of TMB-high, MSI-high, and HRD analyzed by NGS panel in various solid tumors. TMB tumor mutational burden, $M S I$ microsatellite instability, HRD homologous recombination deficiency

Table 2 Prevalence of homologous recombination deficiency (HRD) and use of immune check point inhibitors (ICIs) according to tumor type

\begin{tabular}{lll}
\hline Tumor type & HR deficiency & ICIs \\
\hline Colorectal cancer (151) & $130(86.1 \%)$ & $4(2.6 \%)$ \\
Gastric cancer (116) & $80(69.0 \%)$ & $14(12.1 \%)$ \\
Sarcoma (60) & $39(65.0 \%)$ & $3(5.0 \%)$ \\
Biliary tract cancer (48) & $36(75.0 \%)$ & $5(10.4 \%)$ \\
Pancreatic cancer (42) & $32(76.2 \%)$ & $1(2.4 \%)$ \\
Genitourinary cancer (25) & $23(92.0 \%)$ & $12(48.0 \%)$ \\
Other GI tract cancer ${ }^{\mathrm{a}}(22)$ & $11(50.0 \%)$ & $1(4.5 \%)$ \\
Melanoma (21) & $12(57.1 \%)$ & $20(95.2 \%)$ \\
Hepatocellular carcinoma (12) & $10(83.3 \%)$ & $4(33.3 \%)$ \\
Rare cancer ${ }^{\mathrm{b}}$ (4) & $2(50.0 \%)$ & $1(25.0 \%)$ \\
Total 501 & $375(74.9 \%)$ & $65(13.0 \%)$ \\
\hline a AOV cancer, appendiceal cancer, cecal cancer, duodenal cancer, and \\
GIST \\
${ }^{b}$ Adrenocortical cancer and MUO (malignancy of unknown primary)
\end{tabular}


median. Data are presented as number (\%) for categorical variables. Correlations between status of HRD and clinicopathologic features were analyzed by $t$ test, Fisher's exact test, or one-way analysis of variance (ANOVA), as appropriate. Response categories were assessed according to RECIST 1.1 (Eisenhauer et al. 2009; Schwartz et al. 2016). Objective response rate (ORR) was defined as the percentage of patients with complete response (CR) or partial response (PR). Progression-free survival (PFS) was defined as the interval between the initiation of the treatment and the time of progressive disease (PD). Logistic regression analysis was performed to analyze HRD genes that might be related to treatment response. A Cox regression model was used to analyze the associations of suspecting factors, including HRD and disease progression after ICIs treatment. The Mann-Whitney test was used to compare the difference between HRD and non-HRD. Kaplan-Meier estimates and log-rank tests were used in analysis of all time to event variables, and $95 \%$ confidence interval for the median time to event was computed.
Fig. 2 Prevalence of homologous recombination deficiency (HRD) and HR-related gene mutations in various solid tumors by NGS TruSight. A HRD prevalence by various tumor types in order of highest ratio. $\mathbf{B}$ The observed frequency of HR-related gene variations by NGS panel A, B
A

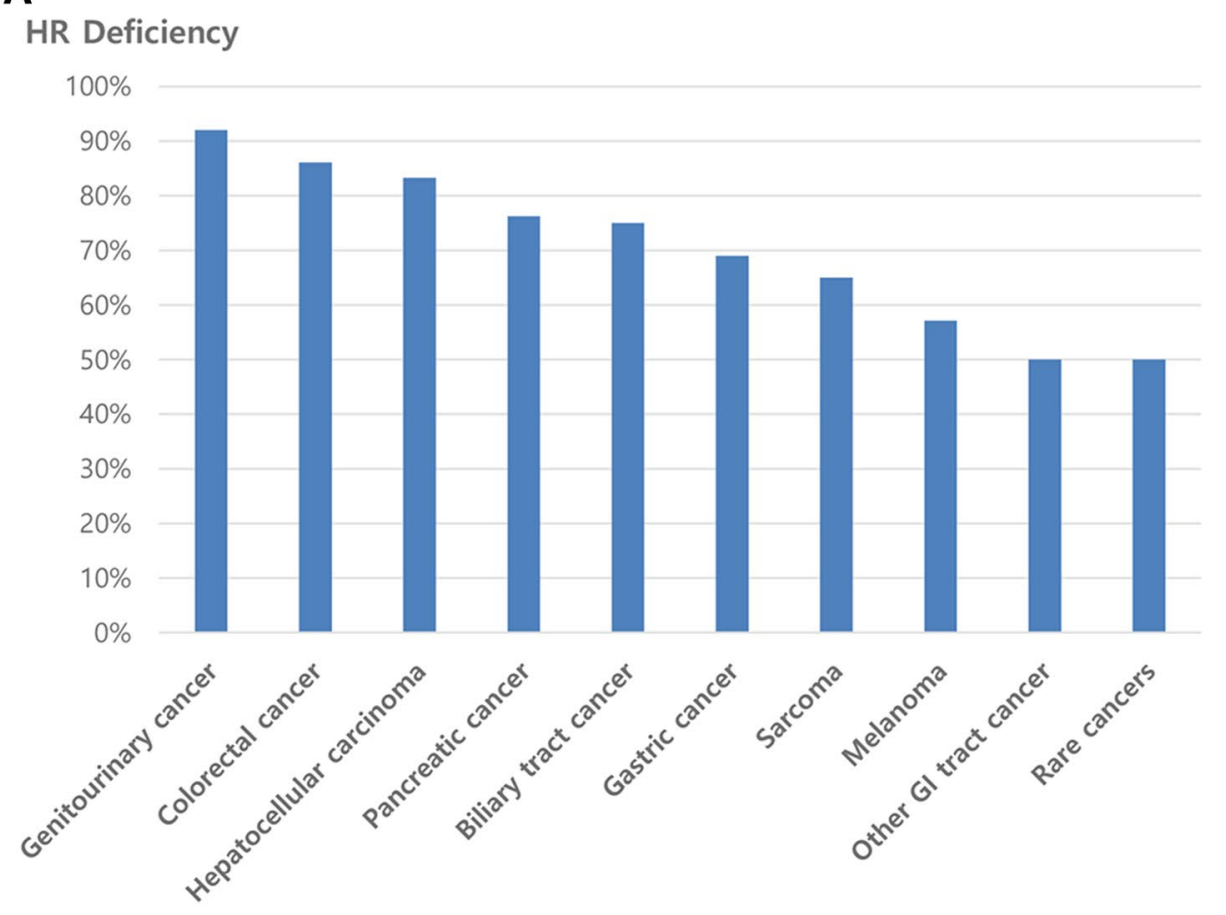

B

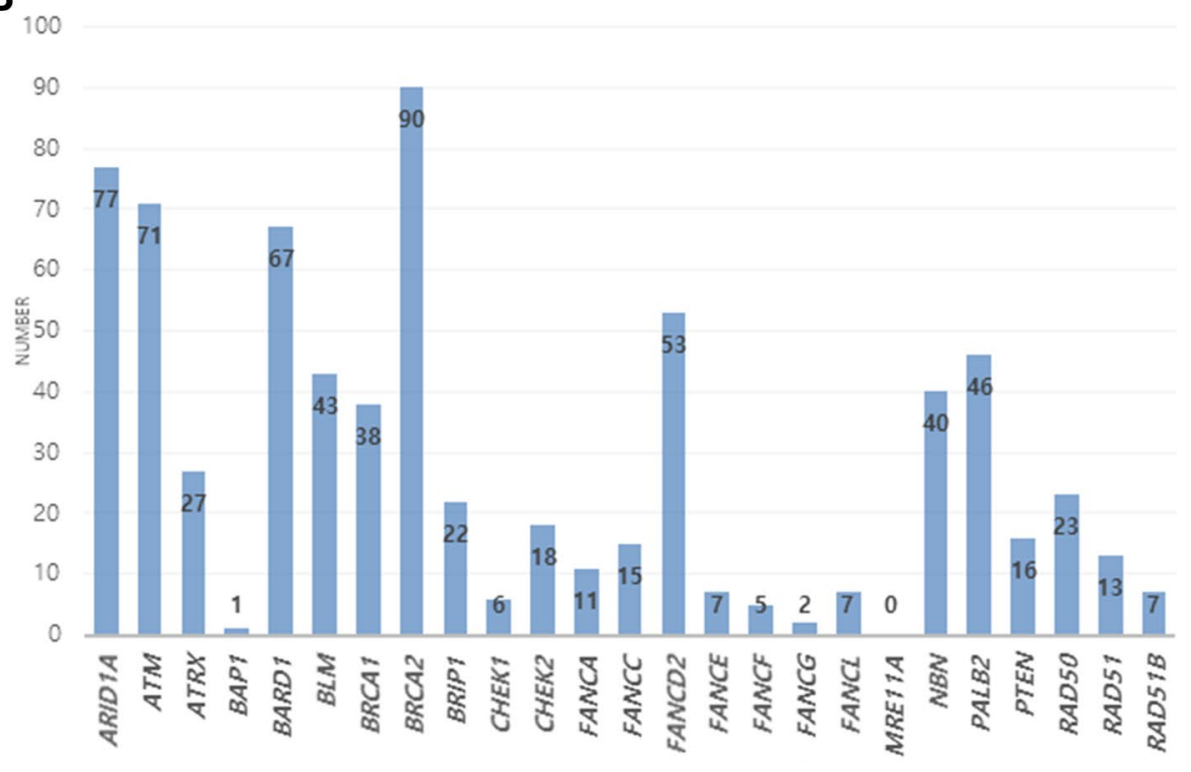




\section{Results}

\section{Patient characteristics}

Table 1 presents the clinical characteristics of the 501 patients included in this study. The median age of the patients was 59.7 years (range, 21-86), and the majority were male $(60.3 \%)$. The median age of males was 61 years, while that of female was 58 years. The most frequent tumor type was colorectal cancer $(n=151,30.1 \%)$, followed by gastric cancer $(n=116,23.2 \%)$, sarcoma $(n=60,12.0 \%)$, pancreatic cancer $(n=42,8.4 \%)$, genitourinary (GU) cancer $(n=25,5.0 \%)$, other gastrointestinal (GI) tract cancer $(n=22,4.4 \%)$, melanoma $(n=21,4.2 \%)$, hepatocellular carcinoma (HCC) $(n=12,2.4 \%)$, and rare cancer $(n=4,0.8 \%)$. Among the 501 patients, 65 had been treated with immune checkpoint inhibitors (ICIs). Figure 1 shows the distribution of TMB, MSI, and HR deficiencies. All seven patients with MSI were TMB-high and HR-deficient. On the other hand, of 375 patients with HR deficiency, only 54 were confirmed to be TMB-high or MSI.

\section{Frequency of tumors with HRD according to type}

Tumors with HRD were observed in 375 of 501 patients irrespective of type. Table 2 presents the status of the HRD and the ratio of patients who received ICI treatment according to tumor type. HR deficiency was observed in $74.9 \%$ of patients with various solid tumors including GU cancer (92.0\%, 23 of 25$)$, CRC $(86.1 \%, 130$ of 151$), \operatorname{HCC}(83.3 \%$, 10 of 12$)$, pancreatic cancer $(76.2 \%, 32$ of 42$)$, biliary tract cancer $(75.0 \%, 36$ of 48$)$, gastric cancer $(69.0 \%, 80$ of 116$)$, sarcoma $(65.0 \%, 39$ of 60$)$, melanoma $(57.1 \%, 12$ of 21$)$, other GI tract cancer (AOV cancer, appendiceal cancer, cecal cancer, duodenal cancer, GIST) $(50.0 \%, 11$ of 22$)$, and rare cancer $(50.0 \%, 2$ of 4$)$. Figure 1 presents the distribution relationship with other biomarkers. All MSI were TMB-high and HR-deficient. However, some TMB-high have no HR deficiency. Figure 2A shows the percentage of confirmed HRD for each tumor type listed in order of high frequency rate. The tumor with the highest frequency of HRD was GU cancer with $92.0 \%$ and the lowest frequency was other GI tract cancer (AOV cancer, appendiceal cancer, cecal cancer, duodenal cancer, and GIST) and rare cancer at $50.0 \%$. The distribution of HRD mutations for each cancer type is included in the supplement. (Supplement S1).

\section{Frequency of HRD according to HR-related genes}

We also analyzed the observed genetic variations by HRrelated genes. (Fig. 2B) The most frequently reported mutations were BRCA2 $(n=90), A R I D 1 A(n=77), A T M(n=71)$, $B A R D 1(n=67)$. On the other hand, FANCG was observed twice and BAPl gene was reported only once. Even MRE11A gene was never observed in 501 patients' NGS results.

\section{Correlations between HRD and disease progression in 65 patients treated with ICls}

Sixty-five patients treated with ICIs at diagnoses as follows: melanoma $(95.2 \%, 20$ of 21$), \mathrm{HCC}(33.3 \%, 4$ of 12$)$, rare cancer $(25.0 \%, 1$ of 4$), \mathrm{GC}(12.2 \%, 14$ of 116$)$, BTC $(10.4 \%$, 5 of 48), and sarcoma (5.0\%, 3 of 60) (Table 2). We analyzed the correlation between HRD and efficacy to ICIs. Patients with HRD exhibited an objective response rate (ORR) of
Fig. 3 Kaplan-Meier curve for Progression-free survival (PFS) after immune checkpoint inhibitors according to homologous recombination deficiency (HRD) status, $(N=65)$

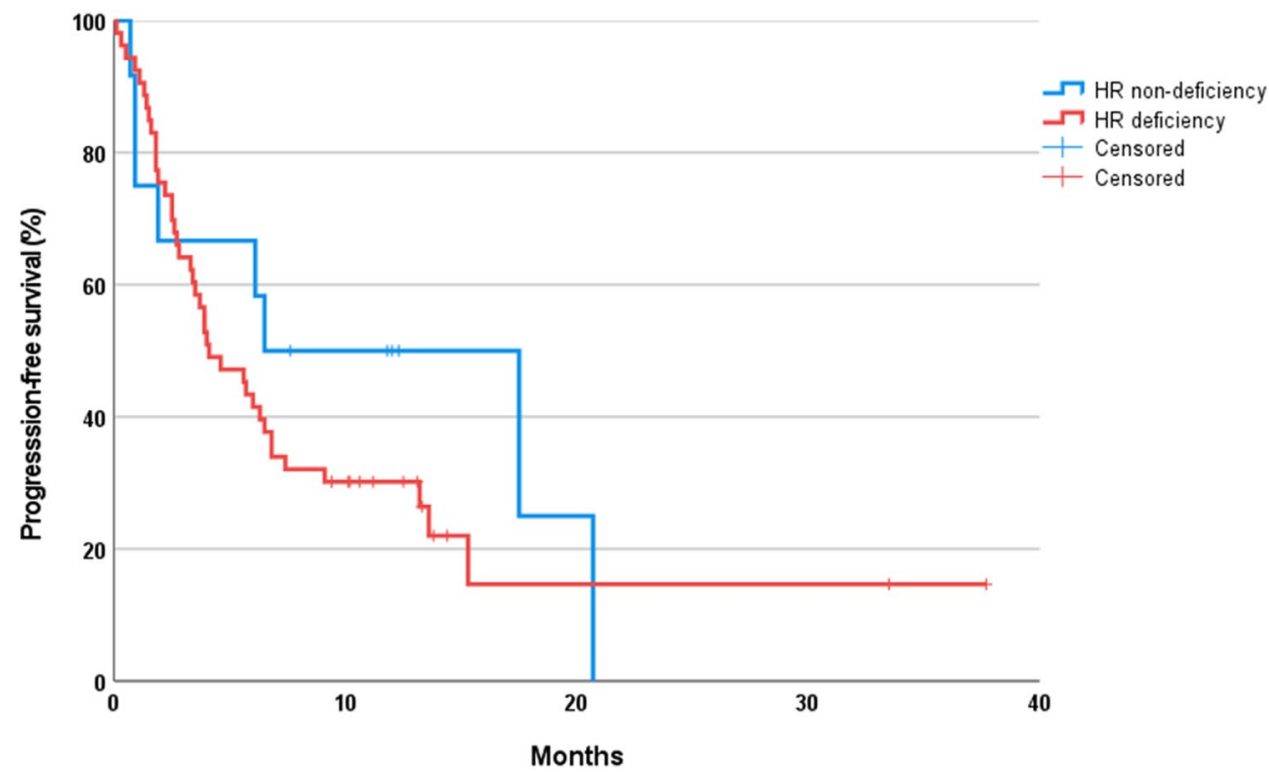


Table 3 Analyses for risk factors affecting progression free survival (PFS) by Cox proportional hazard ratio and objective response to immunotherapy by logistic regression model

\begin{tabular}{|c|c|c|c|}
\hline \multirow[t]{2}{*}{ Variables } & \multirow[t]{2}{*}{ Cases } & \multicolumn{2}{|l|}{ PFS } \\
\hline & & OR $(95.0 \% \mathrm{CI})$ & $P$ \\
\hline \multicolumn{4}{|l|}{ Age } \\
\hline$<65$ & 37 & & \\
\hline$\geq 65$ & 28 & $0.707(0.394-1.267)$ & 0.244 \\
\hline \multicolumn{4}{|l|}{ Smoking } \\
\hline No & 38 & & \\
\hline Yes & 27 & $1.037(0.584-1.842)$ & 0.900 \\
\hline \multicolumn{4}{|l|}{ HRD } \\
\hline 0 (non-deficiency) & 12 & & \\
\hline 1 (deficiency) & 53 & $1.376(0.639-2.963)$ & 0.415 \\
\hline \multicolumn{4}{|l|}{ TMB } \\
\hline Low & 50 & & \\
\hline High & 15 & $0.396(0.182-0.859)$ & 0.019 \\
\hline \multicolumn{4}{|c|}{ Microsatellite instability } \\
\hline Non-MSI & 61 & & \\
\hline MSI & 4 & $0.357(0.086-1.486)$ & 0.157 \\
\hline \multicolumn{4}{|l|}{ PD-L1 by IHC } \\
\hline Negative & 16 & & \\
\hline Positive & 15 & $1.000(0.999-1.000)$ & 0.378 \\
\hline \multirow[t]{2}{*}{ Variables } & Cases & Response to ICIs & \\
\hline & & $\operatorname{Exp}(\beta)(95.0 \% \mathrm{CI})$ & $P$ \\
\hline \multicolumn{4}{|l|}{ Age } \\
\hline$<65$ & 37 & & \\
\hline$\geq 65$ & 28 & $1.157(04,411-3.258)$ & 0.782 \\
\hline \multicolumn{4}{|l|}{ Smoking } \\
\hline No & 38 & & \\
\hline Yes & 27 & $0.722(0.251-2.077)$ & 0.545 \\
\hline \multicolumn{4}{|l|}{ HRD } \\
\hline 0 (non-deficiency) & 12 & & \\
\hline 1 (deficiency) & 53 & $1.029(0.273-3.881)$ & 0.967 \\
\hline \multicolumn{4}{|l|}{ TMB } \\
\hline Low & 50 & & \\
\hline High & 15 & $6.333(1.806-22.204)$ & 0.004 \\
\hline \multicolumn{4}{|c|}{ Microsatellite instability } \\
\hline Non-MSI & 61 & & \\
\hline MSI & 4 & $6.632(0.647-67.964)$ & 0.111 \\
\hline \multicolumn{4}{|l|}{ PD-L1 by IHC } \\
\hline Negative & 16 & & \\
\hline Positive & 15 & $1.000(0.999-1.001)$ & 0.431 \\
\hline
\end{tabular}

$C I$ confidence interval, $O R$ odds ratio, $\operatorname{Exp}(\beta)$ exponentiated coefficient, ICIs immune checkpoint inhibitors

27.3\% (3 of 11), while patients without HRD achieved an ORR of $39.0 \%$ (16 of 41 ).

Progression-free survival (PFS) after ICIs was 6.5 months (95\% CI 0.000-16.175) in patients without HRD and 4.1 months (95\% CI 2.062-6.138) in patients with HRD. This difference was not significant $(P=0.441)$ (Fig. 3).
Detailed data on HRD status and progression for each cancer type are included in the supplement (Supplement S2).

Additionally, we conducted Cox proportional hazard analysis for PFS after ICIs (Table 3). TMB was the only meaningful prognostic factor $(P=0.019)$. Response after immunotherapy was analyzed logistic regression and only 
TMB was revealed to be statistically significant $(P=0.004)$. It has been previously reported in our study that TMB by NGS panel is a useful predictor of immunotherapy (Kim et al. 2021).

\section{Discussion}

In the present study, we evaluated the prevalence of HRD in 501 patients with various solid tumors and investigated the role of HRD as a single biomarker to predict response to ICIs. The overall prevalence of HRD we analyzed was 74.7\% (347/501) and especially, GU cancer and CRC had the HRD of the high frequency. In 65 patients with ICIs, there were no significant differences for ORR and PFS between patients with and without HRD $(P=0.967$ and $P=0.441$, respectively). These findings suggested that HRD as a single biomarker was not sufficient to predict the efficacy of ICIs in solid tumor patients.

The overall frequency of HRD we analyzed was $74.7 \%$ (347/501). This finding was not consistent with other studies about HRD. A previous study reported that the prevalence of HR-DDR mutations was $17.4 \%$ in multiple tumor types (Heeke et al. 2018). This discordance might be caused by different studied genes including different NGS panels and different genes defining HRD. Detection of HRD by the NGS panel has limitations. There is no established definition to assess HRD. Therefore, there are many different results among published papers about the prevalence of HRD. Furthermore, this difference might be caused by discrepancy between measurement of HRD with whole exome sequencing and NGS panels.

There are a few limitations to this study. First, it was a retrospective study, and clinically heterogeneous populations were subject to potential biases. Second, only the Asian population was assessed in the study, so differences in genomic profiles and clinical features between Western and Eastern patients with solid tumors were not considered. Also, this study included a relatively small proportion of patients who had been treated with ICIs, making it difficult to draw definite conclusions regarding biomarkers.

To assess HRD, loss heterozygosity, number of telomeric allelic imbalance and large-scale state transitions are needed (Konstantinopoulos et al. 2015; Patel et al. 2018). However, these parameters are not available in TSO 500 but instead provide point mutations of HR-related genes. Detecting point mutations in HR genes using DNA sequencing panels to identify HR-deficient tumor is previously described (Pellegrino et al. 2020; Polak et al. 2017). In a study with renal cell carcinoma, mutation in HR-related gene associated with higher mutation burden in association with disease control (Labriola et al. 2020) and germline or somatic mutation of $B R C A$ were associate with high mutational burden and showed different genetic character in breast cancer (Lal et al. 2019). The clinical significance of mutation in HR-related genes for application in immunotherapy still needs further investigation with larger cohort and sufficient follow-up period. In addition, future studies on the selection and cutoff value for HR-related gene numbers are also expected, as a biomarker development.

HRD might be a potential candidate predictor of response to ICIs, but the prevalence of HRD has not been investigated across tumor types. The present analysis produced useful information on the prevalence of HRD in various solid tumors under routine clinical practice and demonstrated that HRD as a single biomarker was not sufficient to predict the efficacy of ICIs in solid tumor patients.

\section{Conclusion}

Herein, we reported the status of HRD using a cancer panel for various solid tumor patients in routine clinical practice and demonstrated that HRD as a single biomarker was not sufficient to predict efficacy of ICIs in solid tumor patients.

Supplementary Information The online version contains supplementary material available at https://doi.org/10.1007/s00432-021-03781-6.

Data availability All data that can prove the conclusion of this article are included in the article and the supplements.

\section{Declarations}

Conflict of interest The authors have no conflicts of interest to declare.

Open Access This article is licensed under a Creative Commons Attribution 4.0 International License, which permits use, sharing, adaptation, distribution and reproduction in any medium or format, as long as you give appropriate credit to the original author(s) and the source, provide a link to the Creative Commons licence, and indicate if changes were made. The images or other third party material in this article are included in the article's Creative Commons licence, unless indicated otherwise in a credit line to the material. If material is not included in the article's Creative Commons licence and your intended use is not permitted by statutory regulation or exceeds the permitted use, you will need to obtain permission directly from the copyright holder. To view a copy of this licence, visit http://creativecommons.org/licenses/by/4.0/.

\section{References}

Bartkova J, Horejsi Z, Koed K, Kramer A, Tort F, Zieger K, Guldberg P, Sehested M, Nesland JM, Lukas C, Orntoft T, Lukas J, Bartek J (2005) DNA damage response as a candidate anti-cancer barrier in early human tumorigenesis. Nature 434:864-870. https://doi. org/10.1038/nature03482

Borghaei H, Paz-Ares L, Horn L, Spigel DR, Steins M, Ready NE, Chow LQ, Vokes EE, Felip E, Holgado E, Barlesi F, Kohlhaufl M, Arrieta O, Burgio MA, Fayette J, Lena H, Poddubskaya E, Gerber DE, Gettinger SN, Rudin CM, Rizvi N, Crino L, Blumenschein 
GR Jr, Antonia SJ, Dorange C, Harbison CT, Graf Finckenstein F, Brahmer JR (2015) Nivolumab versus docetaxel in advanced nonsquamous non-small-cell lung cancer. N Engl J Med 373:16271639. https://doi.org/10.1056/NEJMoa1507643

Dunn T, Berry G, Emig-Agius D, Jiang Y, Lei S, Iyer A, Udar N, Chuang HY, Hegarty J, Dickover M, Klotzle B, Robbins J, Bibikova M, Peeters M, Stromberg M (2019) Pisces: an accurate and versatile variant caller for somatic and germline next-generation sequencing data. Bioinformatics 35:1579-1581. https://doi.org/ 10.1093/bioinformatics/bty849

Eisenhauer EA, Therasse P, Bogaerts J, Schwartz LH, Sargent D, Ford R, Dancey J, Arbuck S, Gwyther S, Mooney M, Rubinstein L, Shankar L, Dodd L, Kaplan R, Lacombe D, Verweij J (2009) New response evaluation criteria in solid tumours: revised RECIST guideline (version 1.1). Eur J Cancer 45:228-247. https://doi.org/ 10.1016/j.ejca.2008.10.026

Heeke AL, Pishvaian MJ, Lynce F, Xiu J, Brody JR, Chen WJ, Baker TM, Marshall JL, Isaacs C (2018) Prevalence of homologous recombination-related gene mutations across multiple cancer types. JCO Precis Oncol. https://doi.org/10.1200/PO.17.00286

Hodi FS, O'Day SJ, McDermott DF, Weber RW, Sosman JA, Haanen JB, Gonzalez R, Robert C, Schadendorf D, Hassel JC, Akerley W, van den Eertwegh AJ, Lutzky J, Lorigan P, Vaubel JM, Linette GP, Hogg D, Ottensmeier CH, Lebbe C, Peschel C, Quirt I, Clark JI, Wolchok JD, Weber JS, Tian J, Yellin MJ, Nichol GM, Hoos A, Urba WJ (2010) Improved survival with ipilimumab in patients with metastatic melanoma. N Engl J Med 363:711-723. https:// doi.org/10.1056/NEJMoa1003466

Jeggo PA, Pearl LH, Carr AM (2016) DNA repair, genome stability and cancer: a historical perspective. Nat Rev Cancer 16:35-42. https://doi.org/10.1038/nrc.2015.4

Karczewski KJ, Francioli LC, Tiao G, Cummings BB, Alfoldi J, Wang Q, Collins RL, Laricchia KM, Ganna A, Birnbaum DP, Gauthier LD, Brand H, Solomonson M, Watts NA, Rhodes D, Singer-Berk M, England EM, Seaby EG, Kosmicki JA, Walters RK, Tashman K, Farjoun Y, Banks E, Poterba T, Wang A, Seed C, Whiffin N, Chong JX, Samocha KE, Pierce-Hoffman E, Zappala Z, O'Donnell-Luria AH, Minikel EV, Weisburd B, Lek M, Ware JS, Vittal C, Armean IM, Bergelson L, Cibulskis K, Connolly KM, Covarrubias M, Donnelly S, Ferriera S, Gabriel S, Gentry J, Gupta N, Jeandet T, Kaplan D, Llanwarne C, Munshi R, Novod S, Petrillo N, Roazen D, Ruano-Rubio V, Saltzman A, Schleicher M, Soto J, Tibbetts K, Tolonen C, Wade G, Talkowski ME, Genome Aggregation Database C, Neale BM, Daly MJ, MacArthur DG (2020) The mutational constraint spectrum quantified from variation in 141,456 humans. Nature 581:434-443. https://doi.org/10. 1038/s41586-020-2308-7

Khanna A (2015) DNA damage in cancer therapeutics: a boon or a curse? Cancer Res 75:2133-2138. https://doi.org/10.1158/00085472.CAN-14-3247

Kim H, Hong JY, Lee J, Park SH, Park JO, Park YS, Lim HY, Kang WK, Kim KM, Kim ST (2021) Clinical sequencing to assess tumor mutational burden as a useful biomarker to immunotherapy in various solid tumors. Ther Adv Med Oncol 13:1758835921992992. https://doi.org/10.1177/1758835921992992

Konstantinopoulos PA, Ceccaldi R, Shapiro GI, D'Andrea AD (2015) Homologous recombination deficiency: exploiting the fundamental vulnerability of ovarian cancer. Cancer Discov 5:1137-1154. https://doi.org/10.1158/2159-8290.Cd-15-0714

Labriola MK, Zhu J, Gupta R, McCall S, Jackson J, Kong EF, White JR, Cerqueira G, Gerding K, Simmons JK, George D, Zhang T (2020) Characterization of tumor mutation burden, PD-L1 and DNA repair genes to assess relationship to immune checkpoint inhibitors response in metastatic renal cell carcinoma. J Immunother Cancer. https://doi.org/10.1136/jitc-2019-000319
Lal A, Ramazzotti D, Weng Z, Liu K, Ford JM, Sidow A (2019) Comprehensive genomic characterization of breast tumors with BRCA1 and BRCA2 mutations. BMC Med Genomics 12:84. https://doi.org/10.1186/s12920-019-0545-0

Landrum MJ, Lee JM, Benson M, Brown G, Chao C, Chitipiralla S, Gu B, Hart J, Hoffman D, Hoover J, Jang W, Katz K, Ovetsky M, Riley G, Sethi A, Tully R, Villamarin-Salomon R, Rubinstein W, Maglott DR (2016) ClinVar: public archive of interpretations of clinically relevant variants. Nucleic Acids Res 44:D862-868. https://doi.org/10.1093/nar/gkv1222

Li H (2013) Aligning sequence reads, clone sequences and assembly contigs with BWA-MEM. https://doi.org/10.6084/M9.FIGSH ARE.963153.V1. arXiv:1303.3997v2

Li H, Handsaker B, Wysoker A, Fennell T, Ruan J, Homer N, Marth G, Abecasis G, Durbin R, Genome Project Data Processing S (2009) The Sequence alignment/Map format and SAMtools. Bioinformatics 25:2078-2079

Li MM, Datto M, Duncavage EJ, Kulkarni S, Lindeman NI, Roy S, Tsimberidou AM, Vnencak-Jones CL, Wolff DJ, Younes A, Nikiforova MN (2017) Standards and guidelines for the interpretation and reporting of sequence variants in cancer: a joint consensus recommendation of the association for molecular pathology, American Society of Clinical Oncology, and College of American Pathologists. J Mol Diagn 19:4-23. https://doi.org/10.1016/j. jmoldx.2016.10.002

Motzer RJ, Escudier B, McDermott DF, George S, Hammers HJ, Srinivas S, Tykodi SS, Sosman JA, Procopio G, Plimack ER, Castellano D, Choueiri TK, Gurney H, Donskov F, Bono P, Wagstaff J, Gauler TC, Ueda T, Tomita Y, Schutz FA, Kollmannsberger C, Larkin J, Ravaud A, Simon JS, Xu LA, Waxman IM, Sharma P, CheckMate I (2015) Nivolumab versus everolimus in advanced renal-cell carcinoma. N Engl J Med 373:1803-1813. https://doi. org/10.1056/NEJMoa1510665

Motzer RJ, Tannir NM, McDermott DF, Aren Frontera O, Melichar B, Choueiri TK, Plimack ER, Barthelemy P, Porta C, George S, Powles T, Donskov F, Neiman V, Kollmannsberger CK, Salman P, Gurney H, Hawkins R, Ravaud A, Grimm MO, Bracarda S, Barrios CH, Tomita Y, Castellano D, Rini BI, Chen AC, Mekan S, McHenry MB, Wind-Rotolo M, Doan J, Sharma P, Hammers HJ, Escudier B, CheckMate I (2018) Nivolumab plus ipilimumab versus sunitinib in advanced renal-cell carcinoma. N Engl J Med 378:1277-1290. https://doi.org/10.1056/NEJMoa1712126

Nghiem PT, Bhatia S, Lipson EJ, Kudchadkar RR, Miller NJ, Annamalai L, Berry S, Chartash EK, Daud A, Fling SP, Friedlander PA, Kluger HM, Kohrt HE, Lundgren L, Margolin K, Mitchell A, Olencki T, Pardoll DM, Reddy SA, Shantha EM, Sharfman WH, Sharon E, Shemanski LR, Shinohara MM, Sunshine JC, Taube JM, Thompson JA, Townson SM, Yearley JH, Topalian SL, Cheever MA (2016) PD-1 blockade with pembrolizumab in advanced merkel-cell carcinoma. N Engl J Med 374:2542-2552. https://doi.org/10.1056/NEJMoa1603702

Patel JN, Braicu I, Timms KM, Solimeno C, Tshiaba P, Reid J, Lanchbury JS, Darb-Esfahani S, Ganapathi MK, Sehouli J, Ganapathi RN (2018) Characterisation of homologous recombination deficiency in paired primary and recurrent high-grade serous ovarian cancer. Br J Cancer 119:1060-1066. https://doi.org/10.1038/ s41416-018-0268-6

Pellegrino B, Musolino A, Llop-Guevara A, Serra V, De Silva P, Hlavata Z, Sangiolo D, Willard-Gallo K, Solinas C (2020) Homologous recombination repair deficiency and the immune response in breast cancer: a literature review. Transl Oncol 13:410-422. https://doi.org/10.1016/j.tranon.2019.10.010

Pestinger V, Smith M, Sillo T, Findlay JM, Laes JF, Martin G, Middleton G, Taniere P, Beggs AD (2020) Use of an integrated pan-cancer oncology enrichment next-generation sequencing assay to measure tumour mutational burden and detect clinically 
actionable variants. Mol Diagn Ther 24:339-349. https://doi.org/ 10.1007/s40291-020-00462-x

Polak P, Kim J, Braunstein LZ, Karlic R, Haradhavala NJ, Tiao G, Rosebrock D, Livitz D, Kübler K, Mouw KW, Kamburov A, Maruvka YE, Leshchiner I, Lander ES, Golub TR, Zick A, Orthwein A, Lawrence MS, Batra RN, Caldas C, Haber DA, Laird PW, Shen H, Ellisen LW, D'Andrea AD, Chanock SJ, Foulkes WD, Getz G (2017) A mutational signature reveals alterations underlying deficient homologous recombination repair in breast cancer. Nat Genet 49:1476-1486. https://doi.org/10.1038/ng.3934

Rosenberg JE, Hoffman-Censits J, Powles T, van der Heijden MS, Balar AV, Necchi A, Dawson N, O'Donnell PH, Balmanoukian A, Loriot Y, Srinivas S, Retz MM, Grivas P, Joseph RW, Galsky MD, Fleming MT, Petrylak DP, Perez-Gracia JL, Burris HA, Castellano D, Canil C, Bellmunt J, Bajorin D, Nickles D, Bourgon R, Frampton GM, Cui N, Mariathasan S, Abidoye O, Fine GD, Dreicer R (2016) Atezolizumab in patients with locally advanced and metastatic urothelial carcinoma who have progressed following treatment with platinum-based chemotherapy: a single-arm, multicentre, phase 2 trial. Lancet 387:1909-1920. https://doi.org/ 10.1016/S0140-6736(16)00561-4

Schwartz LH, Litiere S, de Vries E, Ford R, Gwyther S, Mandrekar S, Shankar L, Bogaerts J, Chen A, Dancey J, Hayes W, Hodi FS, Hoekstra OS, Huang EP, Lin N, Liu Y, Therasse P, Wolchok JD, Seymour L (2016) RECIST 1.1-Update and clarification: from the RECIST committee. Eur J Cancer 62:132-137. https://doi.org/10. 1016/j.ejca.2016.03.081
Tutt A, Tovey H, Cheang MCU, Kernaghan S, Kilburn L, Gazinska P, Owen J, Abraham J, Barrett S, Barrett-Lee P, Brown R, Chan S, Dowsett M, Flanagan JM, Fox L, Grigoriadis A, Gutin A, HarperWynne C, Hatton MQ, Hoadley KA, Parikh J, Parker P, Perou CM, Roylance R, Shah V, Shaw A, Smith IE, Timms KM, Wardley AM, Wilson G, Gillett C, Lanchbury JS, Ashworth A, Rahman N, Harries M, Ellis P, Pinder SE, Bliss JM (2018) Carboplatin in BRCA1/2-mutated and triple-negative breast cancer BRCAness subgroups: the TNT trial. Nat Med 24:628-637. https://doi.org/ 10.1038/s41591-018-0009-7

Watkins JA, Irshad S, Grigoriadis A, Tutt AN (2014) Genomic scars as biomarkers of homologous recombination deficiency and drug response in breast and ovarian cancers. Breast Cancer Res 16:211. https://doi.org/10.1186/bcr3670

Wolchok JD, Kluger H, Callahan MK, Postow MA, Rizvi NA, Lesokhin AM, Segal NH, Ariyan CE, Gordon RA, Reed K, Burke MM, Caldwell A, Kronenberg SA, Agunwamba BU, Zhang X, Lowy I, Inzunza HD, Feely W, Horak CE, Hong Q, Korman AJ, Wigginton JM, Gupta A, Sznol M (2013) Nivolumab plus ipilimumab in advanced melanoma. N Engl J Med 369:122-133. https://doi.org/10.1056/NEJMoa1302369

Publisher's Note Springer Nature remains neutral with regard to jurisdictional claims in published maps and institutional affiliations. 